\title{
BMJ Open Correlates of time to clinical presentation for symptomatic individuals with gonorrhoea in South China: results from a cross-sectional study
}

\author{
Peizhen Zhao (D) ,, Juan Nie, ${ }^{1,2}$ Huanhuan Cheng, ${ }^{3}$ Weiming Tang, ${ }^{1,2,4}$ \\ Heping Zheng (D) , ${ }^{1,2}$ Bin Yang, ${ }^{1,2}$ Cheng Wang (I) 1,2
}

To cite: Zhao P, Nie J, Cheng H, et al. Correlates of time to clinical presentation for symptomatic individuals with gonorrhoea in South China: results from a cross-sectional study. BMJ Open 2022;12:e052586. doi:10.1136/ bmjopen-2021-052586

- Prepublication history and additional supplemental material for this paper are available online. To view these files, please visit the journal online (http://dx.doi.org/10.1136/ bmjopen-2021-052586).

Received 20 April 2021 Accepted 08 February 2022

Check for updates

(C) Author(s) (or their employer(s)) 2022. Re-use permitted under CC BY-NC. No commercial re-use. See rights and permissions. Published by BMJ.

For numbered affiliations see end of article.

Correspondence to

Dr Cheng Wang;

wangcheng090705@gmail.com

\section{ABSTRACT}

Objectives This study aimed to determine the variation in the interval between the onset of symptoms and clinical presentation, and its associated factors among symptomatic individuals with gonorrhoea.

Design A cross-sectional study was conducted between 1 June and 30 July 2017.

Setting 129 sexually transmitted disease clinics from 21 cities of Guangdong, China.

Participants Using convenience sampling method to recruit symptomatic individuals with gonorrhoea over 18 years old.

Outcome measure Time to clinical presentation.

Results Among 1664 participants, the median age was 29 (24-36) years old, and the majority were male $(92.5 \%)$ and married $(52.9 \%)$. The median time to clinical presentation was 3 (2-6) days. About 471 (28.3\%) patients had sexual contact while symptomatic. After adjusting for covariates, participants who were female $(\mathrm{a} \beta=0.44,95 \% \mathrm{Cl}: 0.22$ to 0.80 ), from east Guangdong region $(\mathrm{a} \beta=0.44,95 \% \mathrm{Cl}: 0.22$ to 0.80$)$ and had the absence of dysuria ( $\mathrm{a} \beta=0.26,95 \% \mathrm{Cl}$ : 0.06 to 0.46 ) had increased time to clinical presentation. Participants who had commercial sex in the past 6 months $(\mathrm{a} \beta=-0.11$, $95 \% \mathrm{Cl}:-0.21$ to -0.01 ) had decreased time to clinical presentation. Participants who were female (adjusted odds ratio $(\mathrm{aOR})=1.66,95 \% \mathrm{Cl}: 1.08$ to 2.50$)$ and delayed in seeking healthcare more than 7 days $(\mathrm{aOR}=46.71,95 \% \mathrm{Cl}$ : 24.27 to 89.93 ) were more likely to have sexual contact while symptomatic.

Conclusion The time to clinical presentation for individuals with symptomatic gonorrhoea is variable and a high proportion of participants continued to have sexual behaviour while symptomatic. Strategies to increase health literacy may help to minimise the sequelae of gonorrhoea and reduce onward transmission.

\section{INTRODUCTION}

Gonorrhoea is the second most common bacterial sexually transmitted disease (STD) globally, with an incidence of 86.9 million among adults aged 15-49 years in 2016. ${ }^{12}$ In
Strengths and limitations of this study

- This study evaluated the time to clinical presentation by recruiting a large sample among symptomatic individuals with gonorrhoea from 129 sexually transmitted disease clinics in China.

- Generalised linear regression was used to explore factors associated with time to clinical presentation.

- This study was conducted in Guangdong, one of the most economically developed provinces in China, lacking generalisability is a limitation of this study.

- All the data were collected through self-report questionnaire, which may be prone to information bias.

China, new cases of gonorrhoea were reported with steady increase from 100245 in $2015^{3}$ to 117938 in 2019. ${ }^{4}$ This increase causes public health concern, given the risk for serious health outcomes from untreated infections and antimicrobial resistance. ${ }^{5}$

Decreasing the interval between the onset of symptoms and clinical presentation is crucial in reducing the risk of clinical sequelae including pelvic inflammatory disease, tubal infertility and ectopic pregnancy, ${ }^{6}$ onward gonorrhoea transmission and the likelihood of contracting or transmitting HIV. ${ }^{78}$ Previous studies have shown that there are substantial numbers of patients who continue to engage in risky sexual behaviour after the onset of STD symptoms, ${ }^{6}$ which increases the risk of transmitting gonorrhoea to their sexual partners. ${ }^{9-11}$

The time to clinical presentation for gonorrhoea can be highly variable ranging from 1 day to a year. ${ }^{6}$ Previous studies conducted in Germany, ${ }^{12}$ America $^{13}$ and England $^{6}$ suggested that reasons for delaying in seeking healthcare for gonorrhoea may include the high proportion of asymptomatic infections, 
the social stigma and the lack of a sensitive and specific test suitable for mass screening. However, previous studies have many limitations including the small sample sizes, retrospective studies and mainly focused on high-income countries, ${ }^{6} 1213$ which might raise significant bias. Given the importance of timely treatment for gonorrhoea cases, this study aimed to evaluate the time to clinical presentation and its associated factors among symptomatic individuals with gonorrhoea in Guangdong Province, China.

\section{METHODS}

\section{Study setting}

Guangdong Province, located in South China, has a gonorrhoea prevalence of 24.7 per 100000 people, ranking second of all 32 provinces in China in 2019. ${ }^{4}$ The Guangdong government established a STD control and prevention system in Guangdong in 1985. The system, with 21 municipality-level STD control centres and 121 county/district-level STD control centres, covers 3621 health facilities, which included independent STD clinics, general hospital-associated STD clinics, gynaecology and obstetrics clinics, family planning clinics, detention centres for sex workers and drug users and abortion clinics and other healthcare clinics. All the health facilities are walk-in clinics, in which the majority of them accept appointment. All the health facilities can provide HIV/STD testing and consulting services. When infectious diseases such as syphilis and gonorrhoea are diagnosed in those hospitals, these cases must be reported through the National Infectious Disease Surveillance Network. Of these 21 municipalities, seven (Guangzhou, Zhongshan, Zhuhai, Dongguan, Shenzhen, Jiangmen and Foshan) are in the central, more developed area known as the Pearl River Delta. Of the 14 less developed, more resource-constrained municipalities, seven (Chaozhou, Shantou, Jieyang, Shanwei, Huizhou, Heyuan and Meizhou) are in the east of the province, five (Zhaoqing, Yunfu, Yangjiang, Maoming and Zhanjiang) are in the west and two (Qingyuan and Shaoguan) are in the north (Online supplemental figure 1)

\section{Study population}

This cross-sectional study was conducted using convenience sampling method in 129 STD clinics from 21 cities of Guangdong, China between 1 June and 30 July 2017. The 129 public STD clinics were chosen in this study using a probability proportional-to-size sampling method. The number of public patients with gonorrhoea per day at each site was estimated with administrative data.

Patients were eligible for participation if they met the following inclusion criteria: (1) patients who were aged 18 and older; (2) patients who were diagnosed with gonorrhoea; gonorrhoea cases are defined by positive diagnostic tests of Nucleic Acid Amplification Tests; and (3) patients who are willing to participate. Patients who did not have any STD symptoms before seeking healthcare were excluded.
We included the following symptoms as triggers for healthcare seeking for gonorrhoea in men: urethritis (frequent urination, frequent urination tendency or a burning sensation when urinating), a white, yellow or green discharge from the penis, painful or swollen in the penis or testicles or a persistent sore throat. For women, symptoms included urethritis (frequent urination, frequent urination tendency or a painful or burning sensation when urination), increased vaginal discharge, pelvic/lower abdominal pain, pain during sexual activities, postcoital bleeding, persistent sore throat and vaginal bleeding between periods. Some rare symptoms in rectum, throat, joint and eye were included in other symptoms. We reported the top five most common symptoms in the main results. Time to clinical presentation is defined as the self-reported days interval between onset of clinical symptoms of gonorrhoea and first presentation for seeking sexual healthcare. In this study, time to presentation more than 7 days is defined as the delay in healthcare seeking. ${ }^{14}$

\section{Procedures}

From 1 June to 30 July potential study subjects were identified by physicians and research assistants at selected STD clinics. All eligible patients provided written informed consent. For the eligible individuals who agreed to participate in this study and were clinically diagnosed as having gonorrhoea. Outpatient doctors or nurses completed a questionnaire using a face-to-face interview with the patients in a separate and quiet room. The survey took about $5 \mathrm{~min}$. Research participation in this survey was voluntary and no incentives were given to these patients to participate in the study. The participants who filled out the questionnaire received urine, anal or oropharyngeal gonorrhoea testing according to their sexual practices using Nucleic Acid Amplification Tests (Roche Molecular Systems, New Jersey, USA). Standard medical care occurred among patients who received a positive test result on any laboratory sample according to Chinese standard STD clinical management guidelines. ${ }^{15}$

\section{Measures}

We collected data regarding sociodemographics (age, gender, marital status, sexual orientation, education), sexual behaviours in the last 6 months (number of partners, condom use, commercial sexual), clinical symptoms and time to presentation. Commercial sex was defined as an exchange of money or goods for sexual services. We also collected the information on the risk of onward transmission defined as the self-reported sexual activity in the time interval between onset of clinical symptoms of gonorrhoea and first presentation for sexual healthcare.

\section{Statistical analyses}

All the survey data were double-entered with logic checks using Epidata V.3.0. Descriptive analysis was performed to describe socio-demographics, sexual behaviours, clinical symptoms and time to clinical presentation. 
Table 1 Demographics and sexual behaviours of individuals with gonorrhoea in Guangdong, China, 2017 ( $n=1664)$

\begin{tabular}{|c|c|c|c|}
\hline Characteristics & Total & $\begin{array}{l}\text { Male } \\
(n=1539) ~ n(\%)\end{array}$ & $\begin{array}{l}\text { Female } \\
(n=125) \text { n (\%) }\end{array}$ \\
\hline $\begin{array}{l}\text { Number of days between symptom onset and healthcare } \\
\text { seeking (median, IQR) }\end{array}$ & $3.0(2.0-6.0)$ & $3.0(2.0-7.0)$ & $5.0(3.0-10.0)$ \\
\hline \multicolumn{4}{|l|}{ Age } \\
\hline$\leq 25$ & $525(31.6)$ & $479(31.1)$ & $46(36.8)$ \\
\hline $26-40$ & $848(51.0)$ & $795(51.7)$ & $53(42.4)$ \\
\hline$>40$ & $291(17.5)$ & $265(17.2)$ & $26(20.8)$ \\
\hline \multicolumn{4}{|l|}{ Marital status } \\
\hline Married & $880(52.9)$ & $798(51.9)$ & $82(65.6)$ \\
\hline Unmarried/widowed/divorced & $784(47.1)$ & $741(48.1)$ & $43(34.4)$ \\
\hline \multicolumn{4}{|l|}{ Highest educational attainment } \\
\hline Primary school and junior high school & $605(36.4)$ & $549(35.7)$ & $56(44.8)$ \\
\hline Senior high school & $645(38.8)$ & $602(39.1)$ & $43(34.4)$ \\
\hline Undergraduate and over & $414(24.8)$ & $388(25.2)$ & $26(20.8)$ \\
\hline \multicolumn{4}{|l|}{ Sexual orientation } \\
\hline Heterosexual & $1603(96.3)$ & $1480(96.2)$ & $123(98.4)$ \\
\hline Gay, bisexual & $61(3.67)$ & $59(3.8)$ & $2(1.6)$ \\
\hline \multicolumn{4}{|l|}{ Geographic regions } \\
\hline Pearl River Delta & $1429(85.9)$ & $1336(86.8)$ & $93(74.4)$ \\
\hline East Guangdong & $69(4.2)$ & $67(4.4)$ & $2(1.6)$ \\
\hline West Guangdong & $63(3.8)$ & $45(2.9)$ & $18(14.4)$ \\
\hline North Guangdong & $103(6.2)$ & $91(5.9)$ & $12(9.6)$ \\
\hline \multicolumn{4}{|l|}{ Previous other STD infections } \\
\hline Yes & $42(2.5)$ & $33(2.1)$ & $9(7.2)$ \\
\hline No & $1662(97.5)$ & $1506(97.9)$ & $116(92.8)$ \\
\hline \multicolumn{4}{|l|}{ Previous gonorrhoea infection } \\
\hline Yes & $21(1.3)$ & $19(1.2)$ & $2(1.6)$ \\
\hline No & $1643(98.7)$ & $1520(98.8)$ & $123(98.4)$ \\
\hline \multicolumn{4}{|l|}{ Top 5 Clinical Symptoms } \\
\hline \multicolumn{4}{|l|}{ Urethral purulent discharge } \\
\hline Yes & $1435(86.2)$ & $1347(87.5)$ & $88(70.4)$ \\
\hline No & $229(13.8)$ & $192(12.5)$ & 37 (29.6) \\
\hline \multicolumn{4}{|l|}{ Dysuria } \\
\hline Yes & $1319(79.3)$ & $1262(82.0)$ & $57(45.6)$ \\
\hline No & $345(20.7)$ & $277(18.0)$ & $68(54.4)$ \\
\hline \multicolumn{4}{|l|}{ Frequent micturition } \\
\hline Yes & $729(43.8)$ & $694(45.1)$ & $35(28.0)$ \\
\hline No & $935(56.2)$ & $845(54.9)$ & $90(72.0)$ \\
\hline \multicolumn{4}{|l|}{ Urgent micturition } \\
\hline Yes & $720(43.3)$ & $685(44.5)$ & $35(28.0)$ \\
\hline No & $944(56.7)$ & $854(55.5)$ & $90(72.0)$ \\
\hline \multicolumn{4}{|l|}{ Redness swelling of the urethra or cervix } \\
\hline Yes & $674(40.5)$ & $620(40.3)$ & $54(43.2)$ \\
\hline No & $990(59.5)$ & $919(59.7)$ & $71(56.8)$ \\
\hline
\end{tabular}


Table 1 Continued

\begin{tabular}{|c|c|c|c|}
\hline Characteristics & Total & $\begin{array}{l}\text { Male } \\
(n=1539) n(\%)\end{array}$ & $\begin{array}{l}\text { Female } \\
(n=125) \text { n (\%) }\end{array}$ \\
\hline \multicolumn{4}{|c|}{ Number of sex partners in the past 6 months } \\
\hline 1 & $783(47.1)$ & $695(45.2)$ & $88(70.4)$ \\
\hline Multiple & $865(52.0)$ & $830(53.9)$ & $35(28.0)$ \\
\hline No & $665(40.0)$ & $560(36.4)$ & $105(84.0)$ \\
\hline Yes & $999(60.0)$ & $979(63.6)$ & $20(16.0)$ \\
\hline \multicolumn{4}{|c|}{ Consistent condom uses in the past 6 months } \\
\hline No & $1540(92.5)$ & 1419 (92.2) & $121(96.8)$ \\
\hline Yes & $124(7.5)$ & $120(7.8)$ & $4(3.2)$ \\
\hline \multicolumn{4}{|c|}{ Having sex while symptomatic } \\
\hline \multicolumn{4}{|c|}{ Number of days between symptom onset and healthcare seeking } \\
\hline $0-1$ & $249(15.0)$ & $234(15.2)$ & $15(12.0)$ \\
\hline $2-3$ & $601(36.1)$ & $574(37.3)$ & $27(21.6)$ \\
\hline $4-7$ & $519(31.2)$ & $479(31.1)$ & $40(32.0)$ \\
\hline$>7$ & $295(17.8)$ & $252(16.4)$ & $43(34.4)$ \\
\hline
\end{tabular}

STD, sexually transmitted disease.

Since the time to clinical presentation does not satisfy the normal distribution, univariate and multivariable generalised linear regression were used to explore factors associated with time to clinical presentation. Univariate and multivariable logistic regression were conducted to explore factors associated with the risk of onward transmission. In the multivariable model, we adjusted for age, gender, education and marital status. A $p$ value $<0.05$ was taken as statistically significant. All data analyses were conducted with SAS (V.9.4, SAS Institute, Cary, North Carolina, USA).

\section{Patient and public involvement}

The participants and general public were not involved in the development of the research question, outcome measures, design, recruitment and conduct of this study.

\section{RESULTS}

Overall, 1955 individuals were approached, 1808 (response rate $=92.5 \%$ ) were recruited in this survey from 21 cities. We excluded those who did not have any gonorrhoea symptoms $(\mathrm{n}=139)$ and with negative testing results $(n=5)$. Finally, we included 1664 eligible symptomatic individuals with gonorrhoea from 20 cities in Guangdong in this study.

\section{Participants' characteristics and sexual behaviours}

The majority of individuals with gonorrhoea were between 26 and 40 years old $(51.0 \%, 848 / 1664)$, male
$(92.5 \%, \quad 1539 / 1664)$, married $(52.9 \%, 880 / 1664)$, heterosexual $(96.3 \%, 1603 / 1664)$, had a senior highschool degree $(63.6 \%, 1059 / 1664)$ and came from the Pearl River Delta area $(85.9 \%, 1429 / 1664)$. Most of the individuals with gonorrhoea had commercial sex $(60.0 \%$, 999/1664), multiple sexual partners $(52.0 \%, 865 / 1664)$ and not used condoms consistently in the past 6 months $(92.5 \%, 1540 / 1664)$. About one-third of patients $(28.3 \%$, $471 / 1664$ ) had sex during the time interval between onset of clinical symptoms of gonorrhoea and first presentation for sexual healthcare (table 1).

\section{Clinical symptoms}

Of 1664 individuals, most participants had symptom of urethral purulent discharge $(86.2 \%, 1435 / 1664)$ and the symptom of dysuria $(79.3 \%, 1319 / 1664)$. Around half of the participants had symptoms of frequent micturition $(43.8 \%, 729 / 1664)$, urgent micturition $(43.3 \%$, $720 / 1664)$ and redness swelling of the urethra or cervix $(40.5 \%, 674 / 1664)$. Only $2.5 \%(42 / 1664)$ of the participants reported a previous STD infection (table 1).

\section{Description of time to clinical presentation}

The median time to clinical presentation was 3 days with an IQR of 2-6 days. The longest days for seeking healthcare for gonorrhoea was 182 days. The majority of participants sought healthcare within 2-3 days $(36.1 \%, 601 / 1664)$, followed by $4-7(31.2 \%, 519 / 1664)$. The majority of patients $(82.3 \%, 1369 / 1664)$ seek medical treatment 


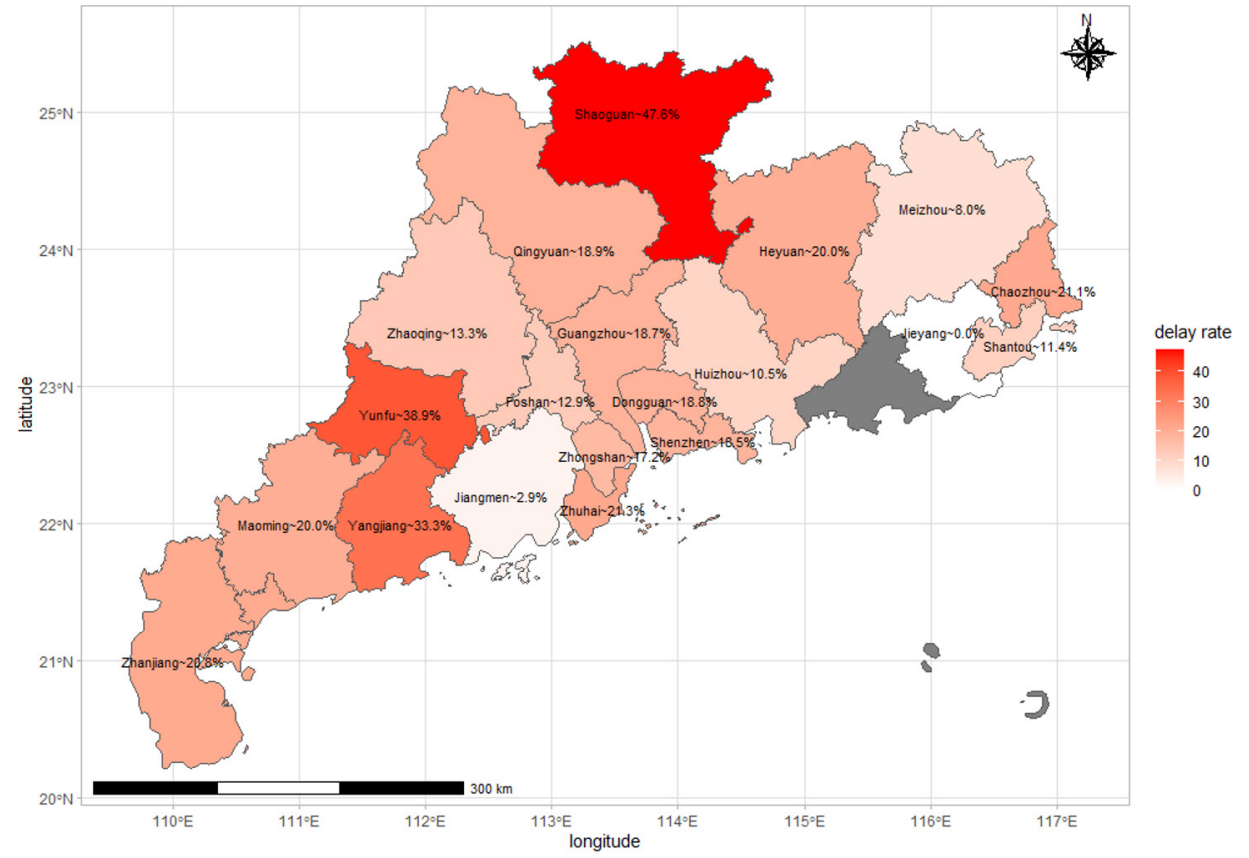

Figure 1 Geographic differences in the proportion of participants who delayed seeking healthcare more than 7 days in Guangdong, China.

within a week. A proportion of $17.8 \%(295 / 1664)$ participants delayed seeking healthcare for longer than 7 days (table 1). Shaoguan city (west of Guangdong) and Yunfu city (north of Guangdong) had the highest proportion of participants who delayed in seeking healthcare for longer than 7 days $(47.6 \%$ and $38.9 \%$, respectively) (figure 1$)$.

\section{Factors associated with time to presentation}

After adjusted for age, gender, education and marital status, multivariable generalised linear regression analysis indicated that participants who were female $(\mathrm{a} \beta=0.44$, 95\% CI: 0.22 to 0.80 ), from east Guangdong region $(\mathrm{a} \beta=0.44,95 \%$ CI: 0.22 to 0.80$)$ and had the absence of dysuria ( $\mathrm{a} \beta=0.26,95 \%$ CI: 0.06 to 0.46 ) increased the time to clinical presentation. Individuals who had commercial sex in the past 6 months $(a \beta=-0.11,95 \%$ CI: -0.21 to -0.01 ) had decreased time to clinical presentation (table 2).

\section{Factors associated with time to presentation stratified by gender}

For male, multivariable generalised linear regression analysis indicated that participants who were from east Guangdong region $(\mathrm{a} \beta=0.54,95 \% \mathrm{CI}$ : 0.21 to 0.86$)$, had the absence of dysuria ( $a \beta=0.22,95 \%$ CI: 0.00 to 0.45 ) which increased the time to clinical presentation. For females, multivariable generalised linear regression analysis indicated that participants who were unmarried/ widowed/divorced ( $a \beta=-1.04,95 \%$ CI: -1.89 to -0.19 ) had decreased time to clinical presentation (Online supplemental table 1)

\section{Factors associated with onward transmission risk}

After adjusted for age, gender, education and marital status, multivariable logistic regression analysis indicated that participants who were female (adjusted odds ratio $(\mathrm{aOR})=1.66,95 \%$ CI: 1.08 to 2.50$)$ and delayed in seeking healthcare more than 7 days $(\mathrm{aOR}=46.71,95 \%$ CI: 24.27 to 89.93) had higher odds of having sexual contact while symptomatic (Table 3 ).

\section{Factors associated with onward transmission risk stratified by gender}

For males, multivariable logistic regression analysis indicated that participants who delayed in seeking healthcare more than 7 days $(\mathrm{aOR}=45.24,95 \%$ CI: 23.31 to 87.79 ) had higher odds of having sexual contact while symptomatic (Table 3). For females, multivariable logistic regression analysis did not find significant indicators (Online supplemental table 2).

\section{DISCUSSION}

Our study suggested that symptomatic patients with gonorrhoea may delay healthcare seeking for a considerable length of time. This study extended the existing literature by evaluating the time to clinical presentation and associated factors using a large sample among symptomatic individuals with gonorrhoea in China. Findings from this study have implications for optimising the management of gonorrhoea in China.

We found that nearly one-fifth of the participants delayed seeking healthcare for more than 7 days after the onset of symptoms. This is consistent with the results of another study in China ${ }^{16}$ and the delay rate is lower than previously reported in England ${ }^{6}$ and America. ${ }^{13}$ Previous studies showed that the perceived stigma related to STD testing ${ }^{17}$ and risk of getting $\operatorname{STD}^{618}$ were the main contributors of preventing timely seeking for healthcare. 
Table 2 Factors associated with time to presentation in individuals with gonorrhoea infection in Guangdong, China, 2017 $(n=1664)$

\begin{tabular}{|c|c|c|c|}
\hline Characteristics & $\begin{array}{l}\text { Delay days } \\
\text { (median, IQR) }\end{array}$ & $\mathrm{c \beta}(95 \% \mathrm{Cl})$ & aß $(95 \% \mathrm{Cl})^{*}$ \\
\hline \multicolumn{4}{|l|}{ Age } \\
\hline$\leq 25$ & $4(2-7)$ & Ref & Ref \\
\hline $26-40$ & $3(2-6)$ & $-0.17(-0.38$ to 0.03$)$ & $-0.15(-0.39$ to 0.1$)$ \\
\hline$>40$ & $3(2-7)$ & $-0.10(-0.37$ to 0.18$)$ & $-0.21(-0.55$ to 0.13$)$ \\
\hline \multicolumn{4}{|l|}{ Gender } \\
\hline Male & $3(2-6)$ & Ref & Ref \\
\hline Female & $5(3-10)$ & $0.62(0.39$ to 0.84$) \dagger$ & $0.60(0.37$ to 0.82$) \dagger$ \\
\hline \multicolumn{4}{|l|}{ Marital status } \\
\hline Married & $3(2-6)$ & Ref & Ref \\
\hline Unmarried/widow/divorced & $4(2-6)$ & $0.06(-0.13$ to 0.25$)$ & $-0.04(-0.27$ to 0.20$)$ \\
\hline \multicolumn{4}{|l|}{ Highest educational attainment } \\
\hline Primary school and junior high school & $4(2-7)$ & Ref & Ref \\
\hline Senior high school & $3(2-6)$ & $-0.19(-0.40$ to 0.03$)$ & $-0.16(-0.38$ to 0.06$)$ \\
\hline Undergraduate and over & $3(2-6)$ & $-0.18(-0.42$ to 0.07$)$ & $-0.11(-0.36$ to 0.14$)$ \\
\hline \multicolumn{4}{|l|}{ Sexual orientation } \\
\hline Heterosexual & $3(2-6)$ & Ref & Ref \\
\hline Gay, bisexual & $4(2-5)$ & $-0.23(-0.86$ to 0.40$)$ & $-0.24(-0.88$ to 0.40$)$ \\
\hline \multicolumn{4}{|l|}{ Geographic regions } \\
\hline Pearl River Delta & $3(2-6)$ & Ref & Ref \\
\hline East Guangdong & $3(2-5)$ & 0.38 (0.04 to 0.72$) \dagger$ & $0.42(0.06$ to 0.77$) \dagger$ \\
\hline West Guangdong & $4(2-8)$ & $0.10(-0.36$ to 0.57$)$ & $0.14(-0.61$ to 0.89$)$ \\
\hline North Guangdong & $4(2-7)$ & $0.03(-0.36$ to 0.42$)$ & 0.07 (-0.48 to 0.62$)$ \\
\hline \multicolumn{4}{|l|}{ Previous other STD infections } \\
\hline Yes & $3(2-6)$ & Ref & Ref \\
\hline No & $3(2-6)$ & $-0.07(-0.72$ to 0.58$)$ & $-0.24(-0.9$ to 0.43$)$ \\
\hline \multicolumn{4}{|l|}{ Previous gonorrhoea infection } \\
\hline Yes & $3(2-6)$ & Ref & Ref \\
\hline No & $3(2-6)$ & $-0.09(-0.87$ to 0.68$)$ & $0.01(-0.84$ to 0.85$)$ \\
\hline \multicolumn{4}{|l|}{ Urethral purulent discharge } \\
\hline Yes & $3(2-6)$ & Ref & Ref \\
\hline No & $4(2-8)$ & $0.20(-0.04$ to 0.44$)$ & $0.04(-0.22$ to 0.30$)$ \\
\hline \multicolumn{4}{|l|}{ Dysuria } \\
\hline Yes & $3(2-6)$ & Ref & Ref \\
\hline No & $4(2-7)$ & $0.34(0.14$ to 0.54$) \dagger$ & $0.26(0.06$ to 0.46$) \dagger$ \\
\hline \multicolumn{4}{|l|}{ Frequent micturition } \\
\hline Yes & $3(2-6)$ & Ref & Ref \\
\hline No & $3(2-6)$ & $0.15(-0.04$ to 0.35$)$ & $0.13(-0.06$ to 0.33$)$ \\
\hline \multicolumn{4}{|l|}{ Urgent micturition } \\
\hline Yes & $4(2-6)$ & Ref & Ref \\
\hline No & $3(2-6)$ & $0.16(-0.04$ to 0.35$)$ & $0.13(-0.06$ to 0.33$)$ \\
\hline \multicolumn{4}{|l|}{ Redness swelling of the urethra or cervix } \\
\hline Yes & $4(2-6)$ & Ref & Ref \\
\hline No & $3(2-6)$ & $0.14(-0.06$ to 0.34$)$ & 0.19 (0.00 to 0.39$)$ \\
\hline
\end{tabular}


Table 2 Continued

\begin{tabular}{|c|c|c|c|}
\hline Characteristics & $\begin{array}{l}\text { Delay days } \\
\text { (median, IQR) }\end{array}$ & $\mathrm{c} \beta(95 \% \mathrm{Cl})$ & $\mathrm{a \beta}(95 \% \mathrm{Cl})^{*}$ \\
\hline \multicolumn{4}{|c|}{ Number of sex partners in the past 6 months } \\
\hline 0 & $2(1.5-3.5)$ & Ref & Ref \\
\hline 1 & $3(2-7)$ & $0.75(-1.22$ to 2.74$)$ & $0.74(-1.15$ to 2.64$)$ \\
\hline Multiple & $3(2-6)$ & $0.68(-1.30$ to 2.66$)$ & $0.72(-1.17$ to 2.62$)$ \\
\hline \multicolumn{4}{|c|}{ Having commercial sex in the past 6 months } \\
\hline No & $4(2-7)$ & Ref & Ref \\
\hline Yes & $3(2-6)$ & $-0.21(-0.40$ to 0.02$) \dagger$ & $-0.11(-0.21$ to -0.01$) \dagger$ \\
\hline \multicolumn{4}{|c|}{ Consistent condom uses in the past 6 months } \\
\hline No & $3(2-6)$ & Ref & Ref \\
\hline Yes & $3(2-5)$ & $-0.41(-0.93$ to 0.11$)$ & $-0.40(-0.93$ to 0.13$)$ \\
\hline
\end{tabular}

${ }^{*}$ Age, gender, education and marital status were adjusted for each other; all other variables were adjusted for age, gender, education and marital status.

$\dagger P<0.05$.

Our study found that men, and participants who had commercial sex were more likely to seek healthcare timely. The possible reason may be the noticeable gonorrhoea symptoms in men, and their high perceived risk of getting STD. ${ }^{6}$ Our results highlighted the importance of promoting gonorrhoea screening among high-risk population in China. A previous study shows that gonorrhoea screening is an effective strategy for gonorrhoea control. ${ }^{19}$ Gonorrhoea screening guideline has been released for high-risk populations to promote the testing uptake in many countries, such as USA, ${ }^{20}$ Australia ${ }^{21}$ and England, ${ }^{22}$ yet such a guideline is not available in China. There is an urgent need to introduce national policies to improve the testing uptake of gonorrhoea among highrisk population in China, especially for asymptomatic infected individuals.

Our study found that a significant proportion of participants continued to have unprotected sex in the interval between symptom onset and presenting at the clinic, which could facilitate onward gonorrhoea transmission. This is similar to previous studies in sub-Saharan Africa ${ }^{23}$ and England. ${ }^{6}$ Low health literacy was considered to be an important reason for continued sexual activity while symptomatic, which causes a perception that the symptoms are not serious. ${ }^{18}$ We found that the odds of continuing sexual activity while symptomatic was nearly two times higher in women compared with men. This is consistent with most studies. ${ }^{6}{ }^{24}{ }^{25}$ Potential reasons showed that most women with gonorrhoea do not demonstrate any symptoms, or even with symptoms, they are often mild and can be mistaken for a bladder or vaginal infection. ${ }^{7}$ The gender difference should be taken into account in the future development of gonorrhoea prevention and education programmes.

Our data suggested substantial geographic differences in healthcare-seeking behaviours. Even though some previous studies did not find a significant relationship between geographic differences and delays in seeking healthcare, our data showed that Shaoguan and Yunfu cities had the highest rate of delays in seeking healthcare (around 40\%). As Shaoguan and Yunfu is located in the marginalised mountain areas of Guangdong, with over $60 \%$ mountain areas, the geographical inconvenience might inhibit timely healthcare seeking. Besides, according to the health facilities number in Guangdong in $2019,{ }^{26}$ Yunfu city has the lowest number of health facilities in all the 21 cities. The inaccessibility of health resources might also be the barriers for the healthseeking behaviours among patients with STD. The disproportional distribution in delays behaviour for gonorrhoea might provide implications to policymakers and clinicians to reconsider the allocation of health resources for STD control and outreach activities might be in place to reach more patients with STD symptoms.

Our study has several limitations. First, all the data were collected through self-report, which may be prone to information bias. The interpretation of data in women is limited by the relatively small number included. Second, the participants were not randomly selected in this study, which may limit the external validity of our findings. Third, this study could not account for many factors that likely influence the time to clinical presentation, such as co-infection with other STD and different levels of severity of symptoms.

Nevertheless, findings from this study expand the understanding of health-seeking behaviours on individuals with gonorrhoea. Outreach activities should be enhanced, particularly to the targeted populations with high delay rate, and to shorten the duration between the appearance of symptoms and seeking healthcare. Key messages should be delivered to the public that symptomatic population of STD should be systematically treated in health facilities before having sex with others. Besides, policymakers and clinicians should reconsider the 
Table 3 Factors associated with sexual contact while symptomatic in individuals with gonorrhoea infection in Guangdong, China, $2017(n=1664)$

\begin{tabular}{|c|c|c|c|c|}
\hline \multirow[b]{2}{*}{ Characteristics } & \multicolumn{4}{|c|}{ Sexual contact } \\
\hline & $\begin{array}{l}\text { Yes n (\%) } \\
(n=471)\end{array}$ & $\begin{array}{l}\text { No } n(\%) \\
(n=1193)\end{array}$ & cOR $(95 \% \mathrm{Cl})$ & aOR $(95 \% \mathrm{Cl})^{*}$ \\
\hline \multicolumn{5}{|l|}{ Age } \\
\hline$\leq 25$ & $146(31.0)$ & $379(31.8)$ & Ref & Ref \\
\hline $26-40$ & 235 (49.9) & $613(51.4)$ & 0.99 (0.78 to 1.27$)$ & 1.02 (0.77 to 1.34$)$ \\
\hline$>40$ & $90(19.1)$ & $201(16.9)$ & $1.16(0.85$ to 1.59$)$ & 1.11 (0.76 to 1.61$)$ \\
\hline \multicolumn{5}{|l|}{ Gender } \\
\hline Male & $428(90.9)$ & $1111(93.1)$ & Ref & Ref \\
\hline Female & $43(9.1)$ & $82(6.9)$ & 1.69 (1.11 to 2.54$) \dagger$ & $1.66(1.08$ to 2.50$) \dagger$ \\
\hline \multicolumn{5}{|l|}{ Marital status } \\
\hline Married & $256(54.4)$ & $624(52.3)$ & Ref & Ref \\
\hline Unmarried/widowed/divorced & $215(45.7)$ & $569(47.7)$ & 0.92 (0.74 to 1.14$)$ & 0.98 (0.77 to 1.25$)$ \\
\hline \multicolumn{5}{|l|}{ Highest educational attainment } \\
\hline Primary and junior high school & $181(38.4)$ & $424(35.5)$ & Ref & Ref \\
\hline Senior high school & $188(39.9)$ & $457(38.3)$ & 0.96 (0.76 to 1.23$)$ & 0.78 (0.59 to 1.04$)$ \\
\hline Undergraduate and over & $102(21.7)$ & $312(26.2)$ & 0.77 (0.58 to 1.02$)$ & $0.96(0.74$ to 1.25$)$ \\
\hline \multicolumn{5}{|l|}{ Sexual orientation } \\
\hline Heterosexual & $455(96.6)$ & $1148(96.2)$ & Ref & Ref \\
\hline Gay/bisexual & $16(3.4)$ & $45(3.8)$ & 0.90 (0.50 to 1.60$)$ & 0.94 (0.52 to 1.69$)$ \\
\hline \multicolumn{5}{|l|}{ Geographic regions } \\
\hline Pearl River Delta & $397(84.3)$ & $1032(86.5)$ & Ref & Ref \\
\hline East Guangdong & $18(3.8)$ & $51(4.3)$ & $0.92(0.53$ to 1.59$)$ & 0.88 (0.51 to 1.53$)$ \\
\hline West Guangdong & $24(5.1)$ & $39(3.3)$ & 1.60 (0.95 to 2.70$)$ & $1.43(0.84$ to 2.44$)$ \\
\hline North Guangdong & $32(6.8)$ & $71(6.0)$ & $1.17(0.76$ to 1.81$)$ & $1.11(0.71$ to 1.72$)$ \\
\hline \multicolumn{5}{|l|}{ Previous gonorrhoea infection } \\
\hline No & $466(98.9)$ & $1177(98.7)$ & Ref & Ref \\
\hline Yes & $5(1.1)$ & $16(1.3)$ & 1.27 (0.46 to 3.48$)$ & $1.06(0.93$ to 1.21$)$ \\
\hline \multicolumn{5}{|c|}{ Number of days between symptom onset and healthcare seeking } \\
\hline $0-1$ & $11(2.3)$ & $238(20.0)$ & Ref & Ref \\
\hline $2-3$ & $87(18.5)$ & $514(43.1)$ & $3.66(1.92$ to 6.98$) \dagger$ & 3.71 (1.95 to 7.09$) \dagger$ \\
\hline $4-7$ & $175(37.2)$ & $344(28.8)$ & 11.00 (5.85 to 20.68$) \dagger$ & 11.31 (6.01 to 21.28$) \dagger$ \\
\hline$>7$ & $198(42.0)$ & $97(8.1)$ & 44.14 (23.01 to 84.65$) \dagger$ & 46.71 (24.27 to 89.93$) \dagger$ \\
\hline \multicolumn{5}{|l|}{ Urethral purulent discharge } \\
\hline Yes & $399(84.7)$ & $1036(86.8)$ & Ref & Ref \\
\hline No & $72(15.3)$ & $157(13.2)$ & 1.19 (0.88 to 1.61$)$ & $1.16(0.86$ to 1.58$)$ \\
\hline \multicolumn{5}{|l|}{ Dysuria } \\
\hline Yes & $366(77.7)$ & 953 (79.9) & Ref & Ref \\
\hline No & $105(22.3)$ & $240(20.1)$ & 1.14 (0.88 to 1.48$)$ & $1.10(0.84$ to 1.44$)$ \\
\hline \multicolumn{5}{|l|}{ Frequent micturition } \\
\hline Yes & $202(42.9)$ & $527(44.2)$ & Ref & Ref \\
\hline No & $269(57.1)$ & $666(55.8)$ & 1.05 (0.85 to 1.31$)$ & 1.07 (0.86 to 1.33$)$ \\
\hline \multicolumn{5}{|l|}{ Urgent micturition } \\
\hline Yes & $203(43.1)$ & $517(43.3)$ & Ref & Ref \\
\hline No & $268(56.9)$ & $676(56.7)$ & 1.01 (0.81 to 1.25$)$ & 1.02 (0.82 to 1.27$)$ \\
\hline
\end{tabular}




\begin{tabular}{|c|c|c|c|c|}
\hline \multirow[b]{2}{*}{ Characteristics } & \multicolumn{4}{|c|}{ Sexual contact } \\
\hline & $\begin{array}{l}\text { Yes n }(\%) \\
(n=471)\end{array}$ & $\begin{array}{l}\text { No } n(\%) \\
(n=1193)\end{array}$ & cOR $(95 \% \mathrm{Cl})$ & aOR $(95 \% \mathrm{CI})^{*}$ \\
\hline Yes & $193(41.0)$ & 481 (40.3) & Ref & Ref \\
\hline No & $278(59.0)$ & $712(59.7)$ & $0.97(0.78$ to 1.21$)$ & 1.00 (0.80 to 1.25$)$ \\
\hline
\end{tabular}

${ }^{*}$ Age, gender, education and marital status were adjusted for each other; all other variables were adjusted for age, gender, education and marital status. $\dagger P<0.05$.

allocation of health resources for STD control to address the disproportional delays behaviour for gonorrhoea in different geographic areas.

\section{CONCLUSION}

Our findings showed the time to presentation for patients with symptomatic gonorrhoea is variable and a high proportion of participants continued to have sexual behaviours after the onset of symptoms. Strategies to increase health literacy and improve timely management may help to minimise the sequelae of gonorrhoea and reduce onward transmission. Health resources allocations should be reconsidered to address the disproportional delays in different cities.

\section{Author affiliations}

${ }^{1}$ STD Control Department, Dermatology Hospital of Southern Medical University, Guangzhou, China

${ }^{2}$ STD Control Department, Southern Medical University Institute for Global Health and Sexually Transmitted Diseases, Guangzhou, China

${ }^{3}$ Department of Ophthalmology, Third Affiliated Hospital of Sun Yat-Sen University, Guangzhou, Guangdong, China

${ }^{4}$ Project-China, University of North Carolina at Chapel Hill, Guangzhou, China

AcknowledgmentsWe would like to thank all the doctors in the 21 city-level STD control centres in Guangdong Province, who coordinated the field survey and help implemented this study. Special gratitude would go for Dongping Bao and Rouxuan Ye who provided valuable advice in the manuscript. We thank Wei Zhang for revising the language of the manuscript.

Contributors $\mathrm{PZ}$ and $\mathrm{CW}$ participated in all stages and wrote the manuscript. JN, $\mathrm{HC}, \mathrm{WT}, \mathrm{HZ}$ and BY helped design the study and reviewed the manuscript.

Funding Medical Scientific Research Foundation of Guangdong Province (B2021297, A2019524, A2019402, C2019122).

Disclaimer The funder had no role in study design or data collection, analysis or interpretation.

Competing interests None declared.

Patient consent for publication Not required.

Ethics approval The study was approved by the institutional review boards of the Dermatology Hospital of Southern Medical University (GDDHLS-20181207). An informed consent was obtained from all the participants who agreed to participate in this study.

Provenance and peer review Not commissioned; externally peer reviewed.

Data availability statement Data are available upon reasonable request.

Supplemental material This content has been supplied by the author(s). It has not been vetted by BMJ Publishing Group Limited (BMJ) and may not have been peer-reviewed. Any opinions or recommendations discussed are solely those of the author(s) and are not endorsed by BMJ. BMJ disclaims all liability and responsibility arising from any reliance placed on the content. Where the content includes any translated material, BMJ does not warrant the accuracy and reliability of the translations (including but not limited to local regulations, clinical guidelines, terminology, drug names and drug dosages), and is not responsible for any error and/or omissions arising from translation and adaptation or otherwise.

Open access This is an open access article distributed in accordance with the Creative Commons Attribution Non Commercial (CC BY-NC 4.0) license, which permits others to distribute, remix, adapt, build upon this work non-commercially, and license their derivative works on different terms, provided the original work is properly cited, appropriate credit is given, any changes made indicated, and the use is non-commercial. See: http://creativecommons.org/licenses/by-nc/4.0/.

\section{ORCID iDs}

Peizhen Zhao http://orcid.org/0000-0002-9334-3744

Heping Zheng http://orcid.org/0000-0002-9846-975X

Cheng Wang http://orcid.org/0000-0001-8000-9969

\section{REFERENCES}

1 China CDC. Overview of epidemic of national notifiable infectious disease in 2017; 2017.

2 World Health Organization. Sexually transmitted infections (STIs); 2016.

3 National Health Commission of the People's Republic of China, 2016. Available: http://www.nhc.gov.cn/jkj/s3578/201602/b9217ba14e17 452aad9e45a5bcce6b65.shtml

4 National Health Commission of the People's Republic of China, 2020. Available: http://www.nhc.gov.cn/jkj/s3578/202004/b1519e1bc1a9 $44 \mathrm{fc} 8 \mathrm{ec} 176 \mathrm{db} 600 \mathrm{f} 68 \mathrm{~d} 1$.shtml

5 Qin X, Zhao Y, Chen W, et al. Changing antimicrobial susceptibility and molecular characterisation of Neisseria gonorrhoeae isolates in Guangdong, China: in a background of rapidly rising epidemic. Int $J$ Antimicrob Agents 2019;54:757-65.

6 Ayinde O, Tan W, Hepburn T, et al. Factors associated with time to presentation for individuals with symptomatic uncomplicated genital gonorrhoea: a cross sectional cohort study of GToG trial participants. Sex Transm Infect 2020;96:251-7.

7 Ruan Y, Cao X, Qian H-Z, et al. Syphilis among female sex workers in southwestern China: potential for HIV transmission. Sex Transm Dis 2006;33:719-23.

8 Fleming DT, Wasserheit JN. From epidemiological synergy to public health policy and practice: the contribution of other sexually transmitted diseases to sexual transmission of HIV infection. Sex Transm Infect 1999;75:3-17.

9 Leichliter JS, Lewis DA, Sternberg M, et al. Health care seeking among men with genital ulcer disease in South Africa: correlates and relationship to human immunodeficiency virus-1 and herpes simplex virus type 2 detection and shedding. Sex Transm Dis 2011;38:865-70.

10 Aral SO. Determinants of STD epidemics: implications for phase appropriate intervention strategies. Sex Transm Infect 2002;78 Suppl 1:i3-13.

11 Wasserheit JN, Aral SO. The dynamic topology of sexually transmitted disease epidemics: implications for prevention strategies. $J$ Infect Dis 1996;174 Suppl 2:S201-13.

12 Jansen K, Steffen G, Potthoff A, et al. Sti in times of PreP: high prevalence of Chlamydia, gonorrhea, and Mycoplasma at different 
anatomic sites in men who have sex with men in Germany. BMC Infect Dis 2020;20:110.

13 Malek AM, Chang C-CH, Clark DB, et al. Delay in seeking care for sexually transmitted diseases in young men and women attending a public STD clinic. Open AIDS J 2013;7:7-13.

14 Aaron KJ, Van Der Pol B, Jordan SJ, et al. Delay in seeking health care services after onset of urethritis symptoms in men. Sex Transm Dis 2019;46:317-20.

15 Zheng H, Wang B, Shi Lian QW. National standard of the People's Republic of China: diagnostic criteria for Gonorrhea (GB 20466-2007) Beijing: Standards Press of China; 2007.

16 S C. Influencing factors of delay in seeing a doctor for gonorrhea patients. Modern Preventive Medicine 2005;32:770-1.

17 Lieber E, Li L, Wu Z, et al. HIV/STD stigmatization fears as healthseeking barriers in China. AIDS Behav 2006;10:463-71.

18 Clifton S, Mercer $\mathrm{CH}$, Sonnenberg P, et al. Sti risk perception in the British population and how it relates to sexual behaviour and STI healthcare use: findings from a cross-sectional survey (Natsal-3). EClinicalMedicine 2018;2-3:29-36.

19 Pillay J, Moore A, Rahman P, et al. Screening for Chlamydia and/or gonorrhea in primary health care: protocol for systematic review. Syst Rev 2018;7:248
20 Centers for Disease Control and Prevention. Which STD tests should I get? Available: https://www.cdc.gov/std/prevention/screeningreccs. $\mathrm{htm}$

21 Australasian Sexual Health Alliance. Sti management guidelines; 2018.

22 England Public Health. Guidance for the detection of gonorrhoea in England; 2015.

23 Meyer-Weitz A, Reddy P, Van den Borne HW, et al. Health care seeking behaviour of patients with sexually transmitted diseases: determinants of delay behaviour. Patient Educ Couns 2000;41:263-74.

24 Gerressu M, Mercer CH, Cassell JA, et al. The importance of distinguishing between black Caribbeans and Africans in understanding sexual risk and care-seeking behaviours for sexually transmitted infections: evidence from a large survey of people attending genitourinary medicine clinics in England. J Public Health 2012;34:411-20.

25 Moses S, Ngugi EN, Bradley JE, et al. Health care-seeking behavior related to the transmission of sexually transmitted diseases in Kenya. Am J Public Health 1994;84:1947-51.

26 Guangdong Statistical Yearbook, 2019. Available: http://stats.gd.gov. cn/gdtjnj/content/post_2639622.html 